\title{
Nem Anjo, Nem Demônio: Uma AnÁlise Cultural da Apropriação da OfÉlia dE SHAKESPEARE EM THE FAMILY SHAKESPEARE
}

\author{
Neither angel, nor demon: a cultural analysis of the \\ appropriation of Shakespeare's Ophelia in \\ The Family Shakespeare
}

\author{
Cristiane Busato Smith* \\ O mito do feminino não floresce nas prescrições \\ cuidadosamente forjadas dos sábios, mas na meia-vida vibrante \\ da literatura e arte popular, formas que podem destilar a \\ essência de uma cultura, embora raramente a Alta Cultura \\ as endosse. \\ (NINA AUERBACH)
}

A personagem ofélia da tragédia Hamlet é convencionalmente considerada pela crítica uma personagem menor em uma peça permeada de grandiosidades. Sua história se constrói em torno dos homens de sua vida: de Polônio, seu pai, de Laertes, seu irmão, e de Hamlet, seu amado. Quando privada de seus eixos de referência - o pai morre, o irmão se ausenta e o amado a rejeita e abandona -, Ofélia enlouquece e se suicida, vítima de uma sociedade patriarcal. Analisar Ofélia no texto shakespeareano, portanto, é analisar silêncios, rejeição, repressão, loucura e morte. Sua história é secundária, imersa em silêncios, ofuscada pelo brilho do protagonista e de seus conflitos existenciais. Em que se pese seus silêncios no texto de origem, Ofélia alcançou uma impressionante e talvez perturbadora visibilidade na Inglaterra do século XIX. No teatro, por exemplo, a despeito dos severos cortes que a personagem tradicionalmente recebia nos roteiros cênicos, Ofélia se destacaria justamente pelo seu apelo físico que estabelecia um diálogo

* UTP-UNIANDRADE 
intenso com a pintura. Esta última a tem como verdadeira musa e ofélia será a personagem literária mais ilustrada e pintada ao longo do século (ALTICK, 1985; YOUNG, 2002; SHOWALTER, 1991). A rica representação iconográfica da heroína assume feições de mulheres belas, insanas, castas e mortas que irão encontrar espaço na poesia, no romance e no palco, em um trânsito dinâmico. Ao mesmo tempo, a personagem shakespeareana servirá como modelo de histeria feminina para psiquiatras vitorianos (SHOWALTER, 1991; RHODES, 1999). Ofélia, não seria exagero afirmar, tornase uma tendência significativa na cultura da época: muitas jovens vitorianas também se apropriam de sua figura como modelo para suas cartes-de-visites - vestindo o branco típico de seu vestido e portando coroas de flores (RHODES, 1999); aparece no mercado um pó facial chamado Ophélia que serve para conferir a palidez da moda, ou seja, o branco facial "de Ofélia". o século XIX, para usar um termo de Bachelard, se "ofeliza".

Somando-se aos universos do teatro, da pintura e da psiquiatria, temos a presença de Ofélia no mundo das diversas edições de Hamlet que emergiram na época - adaptações para o teatro, adaptações para crianças, edições familiares, manuais de conduta e burlescos. É na área das edições que este ensaio se detém, com a intenção de analisar a curiosa adaptação a qual a heroína shakespeareana foi submetida em The family Shakespeare pelos irmãos Bowdler. O conceito de "estrutura de sentimento" 1 do pensador, crítico e escritor galês Raymond Williams (1921-1988) será o fio condutor da minha análise ${ }^{2}$.

\section{The FAMily SHAKESPEARE}

Em sua nota explicativa, citada abaixo na íntegra, o médico Thomas Bowdler (1754-1825) discute sua ideia de escrever The Family Shakespeare:

A primeira ideia de The Family Shakespeare veio com a lembrança da maneira pela qual meu pai habitualmente lia para a família.

${ }^{1}$ Ao teorizar a cultura, Raymond Williams vai na contramão de visões elitistas e advoga por uma cultura comum ("ordinary") que designa os significados ou estruturas comuns a uma sociedade, ou seja, seus modos de vida, bem como a sua produção artística e intelectual. Para Williams, o propósito da análise cultural seria o de entender o que uma cultura está expressando: "a experiência real pela qual uma cultura foi vivida"; "o importante elemento comum"; "uma comunidade particular de experiência" (WILLIAMS, 2001, p. 64), ou seja, reconstituir "a estrutura de sentimento". Por estrutura do sentimento, Williams entende os valores compartilhados de um grupo, classe ou sociedade específica. O termo é empregado para descrever uma estrutura discursiva, que é um misto entre o inconsciente cultural coletivo e uma ideologia. $O$ propósito da análise cultural é, dessa forma, o de ler a estrutura de sentimento por meio dos registros documentados, “desde poemas até prédios e moda do vestuário" (WILLIAMS, 2001, p._65). É esta perspectiva democrática de cultura que guia este ensaio.

2 Para uma análise aprofundada da representação de ofélia no século XIX, ver SMITH, Cristiane Busato. Representações da ofélia de Shakespeare na Inglaterra vitoriana: um estudo interdisciplinar. Tese (Doutorado). Universidade Federal do Paraná. Curitiba, 2007. 


\begin{abstract}
Shakspeare (com quem ninguém era mais familiarizado) era assunto freqüente do entretenimento da noite. Quanto à perfeição da leitura, poucos homens se igualavam ao meu pai, e tal era o seu gosto, sua delicadeza e sua rápida discrição que a família escutava com deleite Lear, Hamlet e Otelo, sem saber que essas tragédias incomparáveis continham palavras e expressões impróprias a serem pronunciadas; e, sem dar motivos de suspeita de que quaisquer das partes das peças haviam sido omitidas pelo leitor circunspecto e judicioso.

Mais tarde, me ocorreu que o que o meu pai havia feito, com tanto sucesso e presteza, para a família, eu talvez pudesse, com minhas abilidades inferiores e com a ajuda do tempo e da maturidade, ser capaz de realizar para o benefício do público. Digo, portanto, que se The Family Shakespeare tem algum mérito, ele se originou com meu pai. (BOWDLER, 1861, p. viii).
\end{abstract}

Thomas Bowdler atribui ao seu pai a origem da "sua" ideia de escrever Shakespeare Familiar. Squire Thomas Bowdler (1720?-1785), seu pai, hábil e criteriosamente, $\operatorname{lia}^{3}$ as obras do famoso bardo para a família, omitindo as partes que julgava indecorosas. A família, composta pela esposa e seis filhos, o escutava avidamente. Entretanto, foi somente após meados do século XX, portanto mais de cento e cinquenta anos depois da primeira publicação do The Family Shakespeare, que se descobriu ${ }^{4}$ que havia ouvidos mais atentos que os de Thomas Bowdler. Esses ouvidos pertenciam a Henrietta Bowdler (1750-1830), sua irmã, que teve o mérito e a ideia de re-escrever vinte obras de William Shakespeare. Essa descoberta não representa muito, mas serve, ao menos, para relativizar a interessante história do maior fenômeno editorial shakespeareano do século XIX: a iniciativa partiu de uma mulher. Quanto à Ofélia em específico, ganham-se dois ângulos diversos de apropriação: os da primeira edição de Henrietta (1807) e a posterior readaptada pelo seu irmão Thomas Bowdler.

The Family Shakespeare foi inicialmente publicado em Bath, no mesmo ano de Contos de Shakespeare. Apesar de não ter sido um sucesso absoluto no início como a edição dos Lamb, Shakespeare Familiar se tornou o mais famoso de todos os livros expurgados no século XIX e, trinta anos após sua publicação o sobrenome de seu editor entrou na língua inglesa como verbo, "bowdlerize", que designa o ato de apropriação e "purificação" de textos. The Family Shakespeare edita, deleta, expurga, a seu bel prazer,

${ }^{3}$ Essas soirées de leitura eram hábito das famílias burguesas, que se reuniam em torno da lareira e escutavam geralmente a voz paternal ler os clássicos ou livros considerados adequados para a leitura familiar. O hábito, característico dos séculos XVIII e XIX, é hoje comparável ao costume brasileiro que muitas famílias têm de reunir-se na frente da televisão para assistir às novelas.

${ }^{4}$ Há várias cartas, principalmente de membros da família Bowdler, que atribuem a edição à Henrietta. Ver Perrin (1992, p.76-83). 
vinte peças de Shakespeare. Da mesma forma que outras edições semelhantes, como Contos de Shakespeare, The Family Shakespeare foi, principalmente, o trabalho de uma mulher, Henrietta Maria Bowdler, conhecida na família como "Harriet", que optou por não ter o crédito público e esconder-se atrás do nome de seu irmão.

Grande admiradora de Shakespeare, Henrietta Bowdler, aparentemente, não se contentou com as leituras criteriosas de seu pai, mas foi buscar a sua própria leitura de Shakespeare na rica biblioteca da família Bowdler. As obras que Henrietta leu devem ter-lhe causado um impacto tão grande que ela decide devotar anos de sua vida para, usando um trocadilho hamletiano, "consertar o que estava errado". Henrietta, solteira a vida toda, não foi o único membro intelectualizado da família Bowdler: além de ávidos leitores, juntos publicaram quatorze volumes. As mulheres da família foram incomumente ativas para a sociedade da época, publicando anonimamente. Consta, inclusive, que a mãe de Henrietta inaugurou a tendência da família de publicar livros expurgados 5 , publicando A Commentary on the song of Solomon paraphrased (1755) [Um comentário sobre a canção de Salomão parafraseada]. A filha mais velha, Jane, também publicou um livro de poemas e ensaios. Mas Henrietta é o membro da família Bowdler que mais se destaca e herda os traços puritanos e intelectuais de seus pais - seu primeiro livro foi Sermons on the doctrines and duties of christianity, [Sermóes sobre as doutrinas e deveres do cristianismo], um best-seller que foi reimpresso cinquenta vezes num período de cinquenta e dois anos.

o que essa mulher fascinante e profundamente discreta faz com as vinte peças de Shakespeare é uma mutilação da qual jamais se ouvira falar. A mutilação é efetuada em diversos níveis de "imoralidade", mas o que certamente mais incomodava Henrietta era a irreverência do autor com relação ao nome de Deus e ao emprego de palavras "sexuais". Extremamente religiosa, Henrietta não permite que nenhum personagem de The Family Shakespeare tome o nome de Deus em vão; Deus somente é invocado para tornar uma ocasião solene ainda mais solene. Com relação à terminologia sexual, Henrietta cuida de eliminar até insinuações. Ela poderia ter feito substituições para as palavras consideradas indecorosas, como mais tarde seu irmão faria, mas ela inescrupulosamente cortava falas ou, até mesmo cenas inteiras, se julgasse necessário.

O fato de Henrietta ter publicado anonimamente reflete a precária condição das escritoras na época. As mulheres que queriam publicar por vezes recorriam a pseudônimos masculinos ou à publicação anônima como estratégias. A "alta literatura" pertencia ao universo masculino, de forma

5 Segundo Noel Perrin, a família Bowdler publicou quatorze livros, vários dos quais expurgações (PERRIN, 1992, p. 65). 
que as grandes edições e traduções eram todas efetuadas pelos homens. Também devemos levar em consideração que, muito provavelmente, Henrietta quis preservar sua integridade, uma vez que, para expurgar cenas e palavras indecorosas e imorais, seria indispensável reconhecer a falta de decoro e indecência das palavras e cenas, algo que certamente não cairia bem para uma moça solteira de seu status social.

A primeira edição de The Family Shakespeare, com apenas quarenta e uma cópias impressas, tem um prefácio não assinado e é apenas dois anos mais tarde, na reimpressão de 1809 , que o crédito vai para Thomas Bowdler, cujo nome aparece na capa (o nome de Henrietta nunca apareceu em nenhuma edição). Entretanto, é somente em 1817, conforme indica a correspondência com o grupo editorial da Longman \& Co de Londres (PERRIN, 1992, p. 11), que Thomas começou a trabalhar com a irmã. Provavelmente movido por motivos diretamente inversos aos de sua irmã que desejava manter-se na obscuridade, o médico aposentado Thomas Bowdler, que, curiosamente, não gostava nem de enfermidades, nem de enfermos, busca a celebridade e insiste em publicar no crescente mercado editorial de Londres.

A insistência de Thomas Bowdler deu resultado: o sucesso e prestígio de The Family Shakespeare é tanto que chega a quatro edições e trinta reimpressões. Ampliado para dez volumes e tendo as outras dezesseis peças de Shakespeare adicionadas à seleção que Henrietta havia feito na primeira edição, The Family Shakespeare foi um verdadeiro fenômeno editorial para a época. As vendas até junho de 1900 perfazem quinze mil duzentas e cinquenta cópias. Em 1864, a editora Longman toma a iniciativa de publicar as peças separadamente e vendê-las em escolas - a última edição foi feita em 1914 e, ao todo, foram vendidas cento e cinquenta mil cópias, sem contar as cópias piratas que apareceram nos Estados Unidos e na Escócia.

o segredo de tanto sucesso pode ser traçado nos propósitos explicitados no prefácio de The Family Shakespeare que cito abaixo:

Apesar de as obras de nosso bardo imortal terem sido apresentadas ao público em uma grande variedade de edições, e já ornarem todas as bibliotecas, e deliciarem todos os leitores, eu me orgulho do fato de que a presente publicação possa ainda chamar a atenção e obter a aprovação daqueles que prezam as produções literárias em proporção ao efeito moral e religioso que possam surtir. Acredito que seja universalmente admitido que poucos autores são tão instrutivos como SHAKESPEARE; mas seus mais ardorosos admiradores devem confessar que suas peças contêm muito que é vulgar, e indelicado. [...] Acredito que o leitor não deva lamentar nada do que é omitido. Para aqueles que fazem objeção a tais alterações, há muitas outras edições de SHAKESPEARE "com todas as imperfeições na cabeça" [...] 
SMITH, C. B. NEM ANJO, NEM DEMÔNIO...

\begin{abstract}
[Neste sentido,] [...] nenhuma linha é adicionada, a não ser quando julguei necessário remover tudo que poderia causar justa ofensa às mentes virtuosas e religiosas. [...] Muitas expressões indecentes e vulgares são omitidas; uma cena absurda é cortada; e eu ocasionalmente substituí uma palavra obsoleta por uma de uso comum. [...] Apenas acrescento que é meu sincero desejo [...] que os leitores ingleses possam ver seu SHAKESPEARE "oferecer um espelho à natureza; mostrar a virtude seus próprios traços, ao ridículo sua própria imagem, e à própria idade e ao corpo dos tempos sua forma e aparência". [citação de Hamlet, p.94]. Com esse desejo, a presente publicação, que é feita para ser lida em lugares privados, e ser colocada nas mãos dos jovens de ambos os sexos, é intitulada "SHAKESPEARE FAMILIAR". ${ }^{6}$
\end{abstract}

Como as palavras do prefácio de Henrietta ${ }^{7}$ acima revelam, os objetivos dessa edição são o de omitir "tudo o que é vulgar e indelicado", isto é, as palavras e expressões que fossem consideradas ofensivas e indecorosas para o gosto da época. Cenas também são cortadas com o mesmo objetivo. A ideia é que Shakespeare fosse um Shakespeare familiar, para ser lido, muitas vezes em voz alta para a família toda, inclusive crianças e mulheres de todas as idades. Fazendo um trocadilho com a citação de Hamlet usada no prefácio, The Family Shakespeare oferece um espelho à moral da época, revelando como e o que deveria ser lido. Na realidade, The Family Shakespeare é um bom reflexo da moral burguesa vitoriana que recebeu este Shakespeare mutilado e o tornou extremamente popular. Interessante notar que em vez de sofrer críticas, The Family Shakespeare é aprovado até pelo meio intelectual que, inclusive, elogia a ideia. Mesmo no final do século quando se podia escolher entre quarenta edições expurgadas de Shakespeare, o poeta Swinburne, em 1894, afirma: "Nenhum homem prestou melhor serviço a Shakespeare que o homem que tornou possível colocá-lo nas mãos de crianças inteligentes e imaginativas" (apud LEÃO, 2000, p. 180).

No entanto, não podemos esquecer que o best-seller do Dr. Bowdler e os obscuros quatro volumes publicados na então provinciana cidade de Bath por Henrietta eram bem diferentes, até mesmo no que tange o volume. Thomas editou trinta e seis peças, das quais, dezesseis sozinho. As vinte peças expurgadas por Henrietta foram revistas e passagens inteiras que haviam sido cortadas por Henrietta foram reinseridas por ele. Em muitos aspectos, Preface p. v-ix.

Edição facsimilar The Family Shakespeare. v.1, 1807, London: Richard Cruttwell,

${ }^{7}$ A edição que tenho em mãos é a quarta edição, (BOWDLER, Thomas. The Family Shakspeare. London: Longman, Green, Longman, and Roberts, 1861); já compilada em um volume e publicada em 1861 por Thomas Bowdler. Nesta edição Thomas omitiu o prefácio acima citado. Note-se também, que enquanto Henrietta usava a grafia "Shakespeare", a mesma empregada no prefácio citado acima, Thomas, por outro lado, utilizava "Shakspeare". 
Thomas Bowdler foi muito mais conservador e respeitoso ao texto shakespeareano que sua irmã. Segundo Perrin, Thomas "resgatou as passagens monótonas que ela, por razões estéticas, havia cortado, e restituiu, tanto quanto sua ousadia lhe permitiu, trechos eliminados que beiravam a indecência, mesmo que tivesse que fazer substituições" (PERRIN, 1992, p. 81).

A minha análise de como The Family Shakespeare recriou Ofélia se baseia na $4 .^{\text {a }}$ edição de Thomas Bowdler, que, como confirma a citação acima, suavizou os rígidos cortes que Henrietta havia feito. Apesar de, infelizmente, não ter a rara edição de Henrietta em mãos, gostaria de sublinhar que o exemplo clássico da expurgação shakespeareana feita pelos Bowdler, citado em várias fontes ${ }^{8}$, é a eliminação da possibilidade de que Ofélia teria se suicidado. Henrietta, como expliquei acima, além de extremamente moralista, era muito religiosa e não comprometeu a virtude de ofélia permitindo que cometesse o pecado imperdoável de tirar sua própria vida. Tal qual a Ofélia dos Lamb, a Ofélia de Henrietta deveria reter os seus valores morais e, fragilizada pelo abandono de seu amado e pela morte de seu querido pai, sofre um trágico acidente quando cai nas águas de um riacho e se afoga.

Muito embora Thomas Bowdler tenha, em certa medida, atenuado os cortes de Henrietta no que tange a Ofélia, seu projeto moralizador foi efetuado com muito critério. Adotando um comportamento aparentemente isolado quando comparado a edições semelhantes e não seguindo à risca os propósitos explicitamente declarados no prefácio ${ }^{9}$, Bowdler não cortou todas as palavras consideradas vulgares e indecorosas. Seguindo a tendência vigente do século XIX, Bowdler reinventou Ofélia, mas sua Ofélia se destaca das demais. A diferença principal é que Thomas deixa transparecer que Ofélia havia pecado, como veremos a seguir. Mais importante e de forma curiosa e atípica para as edições adaptadas para a leitura familiar, Thomas permite a possibilidade de que Ofélia tenha se suicidado.

No entanto, ofélia também ocupou um lugar importante no processo de bowdlerização de Thomas Bowdler e ele reserva para ela um dos poucos exemplos de cortes que recebem destaque no prefácio da sua quarta edição, revelando sua preocupação com a representação da heroína, como veremos adiante.

\footnotetext{
${ }^{8}<$ http://en.wikipedia.org/wiki/Thomas Bowdler $>$; <http://www.answers.com/topic/thomasbowdler >; <http://www.experiencefestival.com/a/Thomas_Bowdler_-_Biography/id/619195>; <http:// www.reference.com/browse/wiki/Thomas_Bowdler> (sites foram acessados em 30/09/2008).

${ }^{9}$ A única crítica que The Family Shakespeare sofreu na época é a de que Thomas Bowdler neste caso acredito que os comentadores deveriam estar se referindo, especificamente, às edições de Thomas
} - deveria ter "bowdlerizado" mais as obras de Shakespeare. Ver Perrin (1992, p. 36). 
Seguindo o desenvolvimento do enredo, verificamos que os conselhos dados a Ofélia por seu irmão Laertes e seu pai, Polônio, habitualmente cortados do Ato I, cena iii, são mantidos na íntegra pelos Bowdler. Apesar de esta cena trazer insinuações sexuais, ela também reforça a ideia da autoridade patriarcal do pai e do irmão sobre a irmã/filha, uma "criança inexperiente e ingênua", segundo Polônio (I.iii). As palavras do irmão foram, assim, mantidas e transmitem uma mensagem clara: "Conserva o teu tesouro de pureza / Longe do alcance do desejo." (MENDONÇA, 1995, p. 45$)^{10}$, pois "a jovem mais prudente ainda é pródiga / se exibe os seus encantos ao luar". De uma forma mais contundente ainda, as palavras do pai são quase ameaçadoras, pois as moças não devem acreditar em "armadilhas para apanhar rolas", estas armadilhas são apenas "promessas", "brasas / dão mais luz que calor, e quando morrem - mera promessa - não perdura nada”. A aproximação e as juras de Hamlet são, para Polônio, "simples rogos para fins profanos / soando como preces e murmúrios / para melhor trair". Enfim, a permanência das palavras do texto original dá claramente a ideia do que poderia acontecer àquelas moças que se rendessem à luxúria antes do casamento. Desta ótica, a manutenção de todas as palavras e insinuações da cena funciona praticamente como um manual de reconhecimento de intenções impuras e promessas falsas para as jovens vitorianas que viam no casamento um passaporte para o único tipo de vida socialmente aceito para uma mulher honrada.

A cena do convento, surpreendentemente, também não é cortada; permanecem todas as insinuações de Hamlet, o que acaba por conferir legitimidade às palavras de Laertes e Polônio, ainda que certas insinuações como "Get thee to a nunnery" (Entra para um convento, p. 90) tenham, ao longo de mais de dois séculos, perdido o significado que a palavra "nunnery"11 possuía na época shakespeareana. A cena, sem a imagem do convento como prostíbulo, traz a abominável ideia de que a moça que não se adequasse aos conselhos dos homens de sua família e cuja "beleza transforma[sse] a virtude em libertinagem", que "mostra o impudor como se fosse inocência" (p. 91), poderia acabar solteira, sem filhos e, destino sem retorno para a reputação de uma moça vitoriana: "não escapará à calúnia" (p. 91). Hamlet, nesta cena, confirma os temores do pai e irmão de ofélia, revelando que ele nunca a amou ("Nunca te amei", p. 91) e que ele era "orgulhoso, vingativo e ambicioso; com mais erros ao [seu] alcance do que pensamentos para expressá-lo". As palavras agressivas de Hamlet rejeitam totalmente o amor de Ofélia e transmitem a clara decisão do Príncipe de não casar com ela: "não haverá mais casamentos" - algo abominável, já que o casamento e a maternidade eram os destinos almejados pelas jovens burguesas no século XIX.

\footnotetext{
${ }^{10}$ Uso a edição de Hamlet traduzida por Anna Amélia Carneiro de Mendonça. As citações que seguem serão seguidas da página correspondente.

11 A palavra "nunnery", na época de Shakespeare, de acordo com os editores de Hamlet Harold Jenkins e Gill Roma, das edições Arden e Oxford, respectivamente, além de significar convento, também significava bordel.
} 
Após essas primeiras cenas, todas as outras são severamente cortadas no intuito de conferir lógica ao discurso moralizador do pai e do irmão e, paralelamente, para reafirmar a ideia da rejeição de Hamlet na cena do convento (III.i.). É interessante, também, observar que as cenas mais expurgadas são aquelas em que Ofélia interage mais ativamente.

As expressões indecorosas que Hamlet dirige à Ofélia na cena da peça-dentro-da-peça (III.ii.) segundo o prefácio de Thomas Bowdler, são como "ervas daninhas que cresceram ao lado de flores", e, uma vez "removidas, [as flores] aparecerão com uma beleza adicional" Assim, "é impossível que qualquer pessoa se ressinta da omissão das palavras indecentes que Hamlet dirige à Ofélia antes da representação da peça" (BOWDLER, 1861, p. vi). Deste modo, como já advertem as palavras de Bowdler na introdução, "desaparecem" as insinuações sexuais do príncipe Hamlet, seguindo a tradição de cortes que as cenas de Ofélia sofriam na época. Fica a impressão de que Ofélia, agora, era tão-somente uma companheira-espectadora de uma peça de teatro que se descortinava para os dois, que nada mais poderia ser feito para recuperar sua honra, que sua oportunidade com Hamlet havia sido desperdiçada por ela não ter, possivelmente, seguido os conselhos de seu pai e irmão.

A cena seguinte de ofélia é a cena da loucura e, como na anterior, todas as insinuações sexuais de Ofélia são omitidas. A ideia que temos é a de que ofélia aparenta ter enlouquecido por causa da morte do pai (assassinado por Hamlet). Indiretamente, lembramos das palavras de Laertes em relação a Hamlet: "ele é nobre e assim sua vontade / não lhe pertence, antes à sua estirpe", ou seja, infere-se que Hamlet agiu conforme a sua estirpe ao matar o pai de Ofélia, não se importando minimamente com os seus sentimentos. Em suma, com a morte do pai, sem a presença do irmão e com a promessa de casamento com Hamlet claramente descartada, possivelmente por ter-lhe "dado o coração" (p. 45) e não ter ficado "longe do alcance do desejo", Ofélia enlouquece. Ora, segundo os rígidos padrões da cultura da época, o que restaria a uma moça rejeitada, sem a proteção dos homens de sua família e sem a esperança de casamento?

Por fim, a descrição da morte de Ofélia retira as duas linhas: "A que os pastores dão um nome obsceno / E as virgens chamam "dedos de defunto ${ }^{12}$ " tipicamente eliminadas dos textos bowdlerizados. Desta forma, apesar de o tema ser a morte, este é abrandado pela descrição que mantém a poesia de Shakespeare, mas elimina o lado obsceno efetuando a função moralizante de The Family Shakespeare.

${ }^{12}$ Os "dedos de defunto", long purples em inglês, são plantas usualmente identificadas como uma espécie de orquídea selvagem. Jenkins afirma que os registros botânicos da época de Shakespeare relacionamna a algumas espécies de tubérculos com formato de testículos (L. testiculus canis), cuja imagem está também presente na origem da palavra grega orchis, que quer dizer testículos (JENKINS, 1982, p. 374). Thomson e Taylor observam que as longas hastes dos "dedos de defunto" podem ser associadas ao formato fálico (THOMPSON; TAYLOR, 2006, p. 407). 
A segunda versão sobre a morte de Ofélia, o suicídio, aventado pelos coveiros, é mantida ipsis litteris por Thomas Bowdler, diferindo quase completamente da primeira edição escrita por sua irmã. Observamos, portanto, que há uma construção mais masculina e patriarcal sobre o pecado feminino: para a mulher, não há redenção. O pecado se traduz em autodestruição.

A Ofélia de The Family Shakespeare se destaca das Ofélias de edições familiares e das Ofélias dos palcos, pois sofreu mutilações textuais menos radicais. A permanência das cenas em que Ofélia recebe os conselhos de Laertes e de Polônio e da cena do convento (III.i) na qual Hamlet a rejeita é importante, uma vez que ilustra claramente como a palavra patriarcal deve ser ouvida. Hamlet, como o pai e o irmão haviam previsto, rejeita Ofélia cruelmente e a abandona. É também importante ressaltar que as duas cenas que permanecem inalteradas são aquelas em que os homens falam e Ofélia meramente responde. Constata-se que Thomas Bowdler rejeita, principalmente, as palavras e insinuações obscenas que saem da boca de Ofélia. A voz de Ofélia, por conseguinte, se torna oca, esvaziada. O projeto moralizador de ofélia feito pelos irmãos Bowdler foi cuidadosamente equilibrado por Thomas Bowdler: algumas insinuações sexuais feitas pelos personagens masculinos ligados a ela diretamente, o pai e o irmão, e, menos diretamente, o namorado, foram mantidas para dar relevo aos conselhos masculinos e ilustrar o que pode acontecer às moças cujo "desejo engana a juventude" (p. 46).

No século da Rainha Vitória, as populares edições familiares de Shakespeare exerceram importante papel ideológico na educação juvenil, principalmente das moças. Para servir o projeto moralizador da época, teve-se que realizar uma verdadeira "limpeza" nas peças de Shakespeare, ou seja, expurgar os textos do que fosse considerado impróprio e indecoroso. Neste processo de adaptação, como explica Pavis,

[t]odas as manobras textuais imagináveis são permitidas: cortes, reorganização da narrativa, "abrandamentos" estilísticos, redução do número de personagem e dos lugares, concentração dramática em alguns momentos fortes, acréscimos e textos externos, montagem e colagem de elementos alheios, modificação da conclusão, modificação da fábula [...] A adaptação [...] goza de grande liberdade; ela não receia modificar o sentido da obra original, de fazê-la dizer o contrário. [...] Adaptar é recriar inteiramente o texto considerado como simples matéria (PAVIS, 1999, p. 10, grifo meu).

Shakespeare foi reinventado, adaptado nos moldes radicais que Pavis descreve acima, pois suas obras tinham que refletir os padrões morais da época. É claro, como adverte Pavis, que essa recriação "nunca é inocente, e sim que implica produção do sentido" (PAVIS, 1999, p. 11). Muitos 
personagens, dessa forma, perdem alguns de seus traços fundamentais e ganham outras características que tentam abrandar aspectos considerados impróprios.

Shakespeare não construiu suas heroínas para funcionarem como modelos de virtudes. A maioria de suas personagens femininas constitui um amálgama de características diferentes que contradizem a virtude angelical que os vitorianos professavam que elas possuíam.

A incrível popularidade de The Family Shakespeare nos mostra que esta publicação teve uma presença significativa no lar burguês. $O$ Shakespeare que se lia era um Shakespeare alterado, domesticado, moldado aos valores morais da época. Os cortes de Ofélia seguem esse princípio e estabelecem um protótipo para as diversas edições bowdlerizadas que seguiram. A versão higienizada e moralizadora de Ofélia veiculada pelos Bowdler propiciou que a personagem ocupasse um lugar de favoritismo entre as heroínas shakespeareanas. Não devemos subestimar, portanto, a importância de edições como The Family Shakespeare: a adequação de Ofélia é um exemplo paradigmático do silenciamento da mulher no século XIX, um período que tentava articular as novas funções sociais para a mulher emergente.

\title{
RESUMO
}

Este artigo recupera a história da apropriação da personagem Ofélia de Shakespeare no século XIX na Inglaterra, focalizando na adaptação feita pelos Bowdler em The Family Shakespeare, o maior fenômeno editorial shakespeareano do século. Analisam-se as permanências e cortes feitas no texto, na tentativa de compreender a política de adaptação que norteou os autores. O conceito de "estrutura de sentimento" de Raymond Williams é empregado para entender a relevância de tal manifestação para a cultura vitoriana.

Palavras-chave: A Ofélia de Shakespeare na cultura vitoriana; The Family Shakespeare; A "estrutura de sentimento" de Raymond Williams.

\begin{abstract}
This article retraces the history of the appropriation of Shakespeare's Ophelia in nineteenth century England, focusing on the Bowdler's adaptation of the heroine in The Family Shakespeare, the biggest Shakespearean editorial phenomenon of the century. In an effort to gauge the politics of adaptation
\end{abstract}


SMITH, C. B. NEM ANJO, NEM DEMÔNIO...

that guided the authors, I analyze the textual manipulation that the Bowdlers undertook. Raymond William's concept of "structure of feeling" will be employed in order to highlight the relevance of such manifestation to the Victorian culture. Keywords: Shakespeare's Ophelia in the Victorian culture; The Family Shakespeare; Raymond Williams's the "structure of feeling."

\section{REFERÊNCIAS}

ALTICK, Richard. D. Paintings from books: art and literature in Britain 1760-1900. Columbus: Ohio State University Press, 1985.

AUERBACH, Nina. Woman and the demon: the life of a Victorian myth. Cambridge: Harvard University Press, 1982.

BOWDLER, Thomas. The family Shakspeare. 4.ed. London: Longman, Green, Longman, and Brothers, 1861.

BRONFEN, Elisabeth. Over her dead body: death, femininity and the aesthetic. Manchester: Manchester University Press, 1996.

DIJKSTRA, Bram. Idols of perversity: fantasies of feminine evil in fin-de-siecle culture. Oxford: Oxford University Press, 1988.

GILBERT, Sandra; GUBAR, Susan. The madwoman in the attic: the woman writer and the nineteenth-century literary imagination. New Haven: Yale University Press, 2000.

JENKINS, Harold. (Ed.). Hamlet: Arden Shakespeare. Walton-on-Thames: Methuen \& Co. Ltd, 1997.

LEÃo, Liana. A plasticidade de A Tempestade: a figura de Caliban. Tese (Doutorado) Universidade de São Paulo. São Paulo, 2000.

MENDONÇA, Anna Amélia Carneiro. de (Tr.) Hamlet. Rio de Janeiro: Nova Fronteira, 1995.

PAVIS, Patrice. Dicionário de teatro. São Paulo: Perspectiva, 1999.

PERRIN, Noel. Dr. Bowdler's legacy: a history of expurgated books in England and America. Boston: David R. Godine, 1992.

RHODES, Kimberley. Performing roles: images of Ophelia in Britain, 1740-1910. Thesis (Ph.D.) - Columbia University. New York, 1999.

SHOWALTER, Elaine. Representing Ophelia: women, madness, and the responsibilities of feminist criticism. In: PARKER, Patricia; HARTMAN, Geoffrey (Ed.). Shakespeare and the Question of Theory. New York: Routledge, 1991.

SMITH, Cristiane Busato. Representações da Ofélia de Shakespeare na Inglaterra vitoriana: um estudo interdisciplinar. Tese (Doutorado) - Universidade Federal do Paraná. Curitiba, 2007.

THOMPSON, Ann; TAYLOR, Neil (Eds.). Hamlet: the Arden Shakespeare. London: Thomson Learning, 2006.

WILLIAMS, Raymond. The long revolution. Toronto: Broadview Press, 2001. 
SMITH, C. B. NEM ANJO, NEM DEMÔNIO...

YOUNG, Alan R. Hamlet in the visual arts 1709-1900. Newark: University of Delaware Press, 2002.

ZIEGLER, Georgianna. Shakespeare's unruly women. Washington: Folger Shakespeare Library, 1997.

Submetido em: 11/10/2008

Aceito em: 10/08/2009 
